\title{
Optimization and Modeling of Leaching Parameters Affecting Nickel Dissolution from Lateritic Ore in Eskisehir (Mihaliccik- Yunusemre) Using Box-Behnken Experimental Design
}

\author{
Tevfik Agacayak ${ }^{1^{*}}$ Mohamed Taha Osman Abdelraheem Ahmed ${ }^{2}$ \\ ${ }^{1}$ Department of Mining Engineering, Konya Technical University, Konya, Turkey \\ ${ }^{2}$ Department of Mining Engineering, Omdurman Islamic University, Khartoum, Sudan
}

\begin{abstract}
In this study, optimization and modeling of leaching parameters affecting nickel dissolution from lateritic ore in Eskişehir (Mihalıçıılk-Yunusemre) were investigated using Box-Behnken design. Stirring speed $\left(100-400 \mathrm{rpm}\right.$, temperature $\left(40-80^{\circ} \mathrm{C}\right)$, acid concentration $(0.1-2 \mathrm{M})$ and dissolution time $(30-180$ min) were selected as experimental design parameters. 27 experiments were carried out by Box-Behnken experimental design in Minitab 16.0 program. After leaching experiments, the highest Ni dissolution percentages were obtained as $87.85 \%$. The effective parameters and their interactions in nickel dissolution are described with a mathematical model. The results obtained from the experiments were subjected to ANOVA and multiple regression analysis. The $\mathrm{R}^{2}$ value of the model for nickel dissolution was calculated as 0.980 . This showed that the predicted values are in good agreement with the observed values. In addition, three-dimensional response surface and contour graphs of the parameters affecting nickel dissolution efficiency were created and the results were examined.
\end{abstract}

Keywords: Nickel $•$ Leaching $•$ Box-behnken design $•$ Optimization

\section{Introduction}

Nickel is an important and strategic metal and mainly used in modern industrial and metallurgical applications because of Its strength and corrosion resistance [1]. Nickel naturally occurs as sulphides and laterites-type ores. Although the lateritic deposits constitute the largest world reserves of nickel, global nickel production has been supplied from sulfide ores due to the challenges of processing laterite compared to sulfide ores $[2,3]$.

The nickeliferous laterite ore deposits are formed by a weathering process. The top of laterite bedrock layer is mainly hematite without a significant nickel content. This is followed by a limonitic zone with $1.5 \%$ nickel. Finally there is a saprolitic layer with up to $4.0 \%$ nickel content $[4,5]$.

There are several reagents used in lateritic nickel extraction such as hydrochloric acid, sulphuric acid, citric acid, nitric acid, ammonia, oxalic acid and acetic acid [6-15]. Several studies have been performed using using Box-Behnken design. Polat and Sayan, studied the struvite precipitation with a Box-Behnken design [16]. Koca et al., studied the evaluation of combined lignite cleaning processes, flotation and microbial treatment, and its modelling by Box Behnken methodology [17]. Ozgen et al., examined the effect of smectite content on swelling to hydrocyclone processing of bentonites with various geologic properties by Box Behnken design [18].

The aim of this study is to optimize leaching parameters affecting nickel dissolution from lateritic ore from Eskişehir (Mihalıççık-Yunusemre) using Box-Behnken design. Stirring speed, temperature, acid concentration and dissolution time were selected as experimental design parameters. The results obtained from the experiments were subjected to ANOVA and multiple regression analysis. In addition, three-dimensional response surface and contour graphs of the parameters affecting nickel dissolution efficiency were created and the results were examined.

\section{Materials and Methods}

\section{Materials}

In this study, sample of lateritic nickel ore taken from MihalıççıYunusemre/Eskişehir in Turkey was used (Figure 1). Approximately $100 \mathrm{~kg}$ of ore samples were brought to the laboratory and crushed to a size of -3.35 $\mathrm{mm}$. The ore was then ground to size less than $106 \mu \mathrm{m}$ by a rod mill. Chemical analysis of the sample was done by AAS (GBC SensAA model). The chemical composition of the sample is given in Table 1.

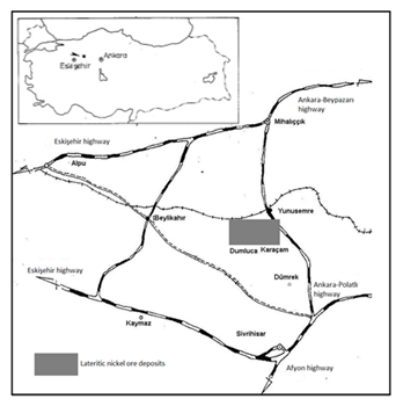

Figure 1. Location of Mihalıççık-Yunusemre/ Eskişehir region in Turkey.

"Corresponding author: Tevfik Agacayak, Department of Mining Engineering, Konya Technical University, Konya, Turkey, Tel: 905434631328; E-mail: tagacayak@ktun.edu.tr

Copyright: ๑ 2020 Agacayak T, et al. This is an open-access article distributed under the terms of the creative commons attribution license which permits unrestricted use, distribution and reproduction in any medium, provided the original author and source are credited. 
Table 1. Chemical analysis of lateritic nickel ore sample.

\begin{tabular}{lllll}
\hline Element & $\mathrm{Ni}$ & $\mathrm{Fe}$ & $\mathrm{Mg}$ & $\mathrm{Co}$ \\
\hline Mass fraction (\%) & 1.84 & 23.14 & 1.58 & 0.03 \\
\hline
\end{tabular}

Mineralogical investigations were carried out on sample by means of $X$ ray diffraction $(\mathrm{XRD})$ analysis, $\mathrm{X}$-ray diffraction $(\mathrm{XRD})$ analysis reaveled that the main minerals are goethite, hematite and wustite. The gangue minerals of the ore are determined as retgersite, gaspeite, quartz and clay type minerals (Figure 2).

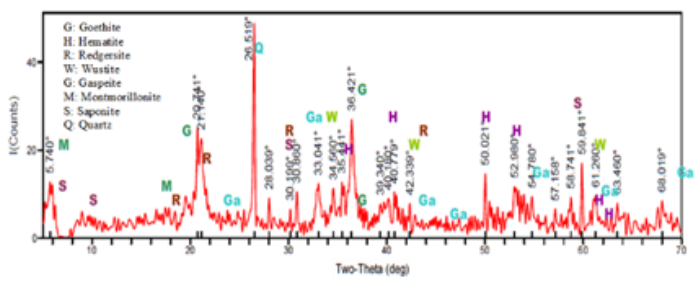

Figure 2. XRD analysis of sample.

\section{Leaching tests}

Experiments were carried out in $1 \mathrm{~L}$ pyrex leach beaker using $10 / 500$ $\mathrm{g} / \mathrm{mL}$ (solid-liquid ratio) in a temperature-controlled water bath. The leach solution was provided by Heidolph mark RZR 2021 model mechanical stirrer with a teflon-covered impeller.

Table 2. Experimental factors and their level.

\begin{tabular}{llllll}
\hline & & & Low value & $\begin{array}{l}\text { Center } \\
\text { value }\end{array}$ & $\begin{array}{l}\text { High } \\
\text { value }\end{array}$ \\
\cline { 4 - 6 } & & Units & & 0 & 1 \\
\hline$X_{1}$ & Stirring speed & rpm & 100 & 200 & 400 \\
\hline$X_{2}$ & Temperature & ${ }^{\circ} \mathrm{C}$ & 40 & 60 & 80 \\
\hline$X_{3}$ & Acid concentration & molar & 0,1 & 0,5 & 2 \\
\hline$X_{4}$ & Dissolution time & min & 30 & 90 & 180 \\
\hline
\end{tabular}

Box-Behnken design method was applied to determine the effects of nickel dissolution parameters from lateritic ore. The leaching studies were performed according to the full factorial design of experiments. The variables studied were stirring speed, temperature, acid concentration and dissolution time. The variables and levels of full factorial design are presented in Table 2. Each variable was studied at three levels: -1 is for low level, +1 denotes high level, and 0 is used for the midpoint to evaluate the experimental error $[16,19]$.

Box-Behnken designs are based on three-level incomplete factoria designs. Graphical representation of Box-Behnken design matrix for three parameters can be seen in Figure 1 [20]. As seen in Figure 3, experiments are usually performed at center levels of parameters. Design Expert Minitab 16.0 program was used for achieving design matrix and obtaining mathematical models of the response variables.

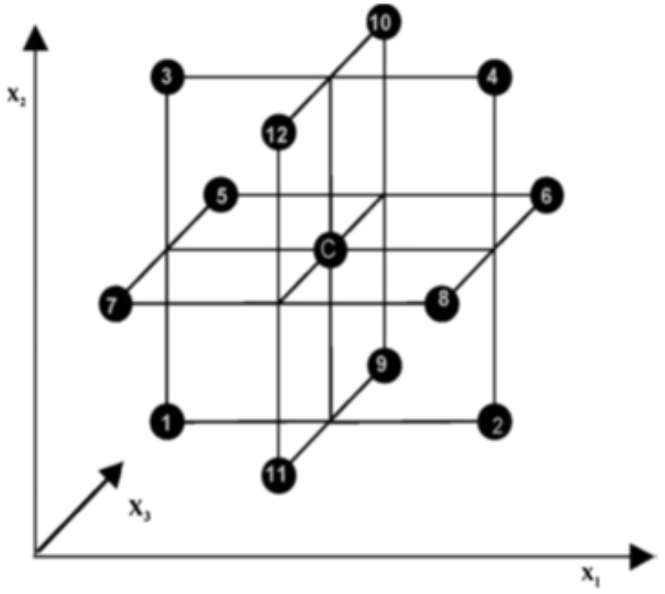

Figure 3. Box-Behnken design with three parameters.

\section{Results and Discussion}

\section{Experimental results for the Box-Behnken design experiments}

A total of 27 tests were carried out according to Box-Behnken experimental design. Experiments were conducted for three levels of 4 variables. Table 3 shows the experimental and estimated $\mathrm{Ni}$ dissolution percentages. The lowest $\mathrm{Ni}$ dissolution percentages obtained from experiments was $7.36 \%$ and the highest test result was $87.85 \%$. The lowest estimated result and highest estimated result were $6.42 \%$ and $81.51 \%$, respectively.

Table 3. Box-Behnken experimental Design table, experimental and estimated $\mathrm{Ni}$ dissolution percentages.

\begin{tabular}{|c|c|c|c|c|c|c|}
\hline \multirow{2}{*}{ Test No } & \multicolumn{4}{|c|}{ Factors } & Test result & \multirow{2}{*}{$\begin{array}{l}\text { Estimated } \\
\mathrm{Ni} \% \\
\end{array}$} \\
\hline & $\mathrm{X}_{1}$ & $x_{2}$ & $x_{3}$ & $x_{4}$ & & \\
\hline 1 & 0 & 0 & 0 & 0 & 23.23 & 23.23 \\
\hline 2 & 1 & 0 & 1 & 0 & 52.81 & 55.23 \\
\hline 3 & 0 & 0 & 1 & -1 & 34.91 & 38.89 \\
\hline 4 & 0 & -1 & 1 & 0 & 45.3 & 40.38 \\
\hline 5 & 0 & 0 & -1 & 1 & 14.33 & 10.58 \\
\hline 6 & -1 & 0 & -1 & 0 & 9.56 & 9.76 \\
\hline 7 & 1 & 1 & 0 & 0 & 42.48 & 40.97 \\
\hline 8 & 0 & 1 & -1 & 0 & 15.83 & 17.91 \\
\hline 9 & 1 & 0 & -1 & 0 & 12.42 & 11.34 \\
\hline 10 & 0 & 1 & 0 & 1 & 47.72 & 49.97 \\
\hline 11 & 0 & 1 & 0 & -1 & 24.62 & 29.16 \\
\hline 12 & -1 & 1 & 0 & 0 & 43.27 & 42.26 \\
\hline 13 & 0 & -1 & -1 & 0 & 8.86 & 12.36 \\
\hline
\end{tabular}




\begin{tabular}{lllllll}
\hline 14 & 0 & 0 & -1 & -1 & 7.36 & 6.42 \\
\hline 15 & 0 & 0 & 0 & 0 & 23.23 & 23.23 \\
\hline 16 & -1 & -1 & 0 & 0 & 16.25 & 17.98 \\
\hline 17 & -1 & 0 & 1 & 0 & 53.81 & 57.51 \\
\hline 19 & 1 & 0 & 0 & -1 & 14.81 & 11.73 \\
\hline 20 & -1 & 0 & 0 & -1 & 22.25 & 17.39 \\
\hline 21 & -1 & 0 & 0 & 1 & 29.35 & 29.59 \\
\hline 22 & 0 & -1 & 0 & -1 & 8.75 & 9.12 \\
\hline 23 & 1 & -1 & 0 & 0 & 17.33 & 18.56 \\
\hline 24 & 0 & 0 & 0 & 0 & 23.23 & 23.23 \\
\hline 25 & 0 & 1 & 1 & 0 & 87.85 & 81.51 \\
\hline 26 & 1 & 0 & 0 & 1 & 32.52 & 34.54 \\
\hline 27 & 0 & -1 & 0 & 1 & 25.24 & 23.32 \\
\hline
\end{tabular}

\section{ANOVA results}

Analysis of variance (ANOVA) based on Box-Behnken experimental design was applied to check the importance and competency of the model coefficient. According to the analysis variance (Table 4), the Fisher's (F-test) with a very low probability value $(P M o d e l>F)<0.0001$ indicates the model is highly significant. When analyzing ANOVA results, a large value of $F$ with a small value of $p$ (i.e., $p<0.05$ ) show that the model is statistically significant, whereas the values greater than 0.1 indicate that the model terms are not significant [21]. It was seen that temperature, acid concentration and dissolution time were significant, whereas Stirring speed, was not significant due to high P-value. P-values for all conditions model are given in Table 4.

Table 4. Analysis of variance for nickel dissolution (Ni\%) (ANOVA).

\begin{tabular}{|c|c|c|c|c|c|c|}
\hline Source & DF & $\begin{array}{l}\text { Sum } \\
\text { Squares }\end{array}$ & of & $\begin{array}{l}\text { Mean } \\
\text { Square }\end{array}$ & F value & P-value Prob $>F$ \\
\hline Regression & 14 & 10038.5 & & 717.04 & 41.31 & $<0.0001^{*}$ \\
\hline Linear & 4 & 8852.2 & & 2213.06 & 127.51 & $<0.0001^{*}$ \\
\hline$X_{1}$ & 1 & 0.4 & & 0.37 & 0.02 & 0.886 \\
\hline$x_{2}$ & 1 & 1634.3 & & 1634.27 & 94.16 & $<0.0001^{*}$ \\
\hline$x_{3}$ & 1 & 6298 & & 6297.96 & 362.87 & $<0.0001^{*}$ \\
\hline$x_{4}$ & 1 & 919.6 & & 919.63 & 52.99 & $<0.0001^{*}$ \\
\hline Square & 4 & 647.8 & & 161.95 & 9.33 & $0.001^{*}$ \\
\hline$X_{1}^{2}$ & 1 & 19.2 & & 6.05 & 0.35 & 0.566 \\
\hline$x_{2}^{2}$ & 1 & 83 & & 169.95 & 9.79 & $0.009^{*}$ \\
\hline$X_{3}{ }^{2}$ & 1 & 540.4 & & 447.62 & 25.79 & $<0.0001^{*}$ \\
\hline
\end{tabular}

\begin{tabular}{llllll}
\hline $\mathrm{X}_{4}{ }^{2}$ & 1 & 5.2 & 5.19 & 0.3 & 0.595 \\
\hline Interaction & 6 & 538.5 & 89.75 & 5.17 & $0.008^{*}$ \\
\hline $\mathrm{X}_{1} \mathrm{X}_{2}$ & 1 & 0.9 & 0.87 & 0.05 & 0.826 \\
\hline $\mathrm{X}_{1} \mathrm{X}_{3}$ & 1 & 3.7 & 3.72 & 0.21 & 0.651 \\
\hline $\mathrm{X}_{1} \mathrm{X}_{4}$ & 1 & 28.1 & 28.14 & 1.62 & 0.227 \\
\hline $\mathrm{X}_{2} \mathrm{X}_{3}$ & 1 & 316.5 & 316.48 & 18.24 & $0.001^{*}$ \\
\hline $\mathrm{X}_{2} \mathrm{X}_{4}$ & 1 & 10.9 & 10.92 & 0.63 & 0.443 \\
\hline $\mathrm{X}_{3} \mathrm{X}_{4}$ & 1 & 178.4 & 178.36 & 10.28 & $0.008^{*}$ \\
\hline Residual & 12 & 208.3 & 17.36 & & \\
\hline Lack of fit & 10 & 208.3 & 20.83 & 624807.17 & $0.0001^{*}$ \\
\hline Pure error & 2 & 0 & 0 & & \\
\hline Total & 26 & 10246.8 & & & \\
\hline
\end{tabular}

* Significant

\section{Regression results}

The results of the regression analysis with Minitab 16.0 software are given in Table 5. The $\mathrm{R}^{2}$ value for nickel dissolution was calculated to be 0.980 , explaining $98 \%$ of the variability in the response. The adjusted $R^{2}$ value was found to be 0.956 . The predicted regression coefficients value ( $R^{2}$ pred) is in very close agreement with the adjusted regression coefficients value ( $\left.R^{2} \mathrm{adj}\right)$, that is because the difference between the two is less than 0.2 [22].

Table 5. Regression values of the optimization study.

\begin{tabular}{ll}
\hline Regression Values & Nickel Dissolution Efficiency (\%) \\
\hline Standard deviation & 0.0416602 \\
\hline R-Squared & 0.98 \\
\hline Adj R-Squared & 0.956 \\
\hline Pred R-Squared & 0.883 \\
\hline
\end{tabular}

Regression coefficients for nickel dissolution (\% Ni) are given in Table 6. From the table, coefficients of acid concentration $\left(X_{3}\right)$, and $X_{2} X_{3}$ seem to be more important for nickel dissolution.

Table 6. Regression coefficients for nickel dissolution (\% Ni).

\begin{tabular}{|c|c|c|c|c|}
\hline Term & Coefficient & $\begin{array}{l}\text { Std. } \\
\text { Coefficient }\end{array}$ & Error $T$ & P-value \\
\hline Constant & 23.2333 & 2.405 & 9.659 & 0.000 \\
\hline$x_{1}$ & -0.1767 & 1.203 & -0.147 & 0.886 \\
\hline$x_{2}$ & 11.67 & 1.203 & 9.704 & 0.000 \\
\hline$x_{3}$ & 22.9092 & 1.203 & 19.049 & 0.000 \\
\hline$X_{4}$ & 8.7542 & 1.203 & 7.279 & 0.000 \\
\hline
\end{tabular}




\begin{tabular}{lllll}
\hline $\mathrm{X}_{1}{ }^{2}$ & 1.065 & 1.804 & 0.590 & 0.566 \\
\hline $\mathrm{X}_{2}{ }^{2}$ & 5.645 & 1.804 & 3.129 & 0.009 \\
\hline $\mathrm{X}_{3}{ }^{2}$ & 9.1612 & 1.804 & 5.078 & 0.000 \\
\hline $\mathrm{X}_{4}{ }^{2}$ & -0.9862 & 1.804 & -0.547 & 0.595 \\
\hline $\mathrm{X}_{1} \mathrm{X}_{2}$ & -0.4675 & 2.083 & -0.224 & 0.826 \\
\hline $\mathrm{X}_{1} \mathrm{X}_{3}$ & -0.965 & 2.083 & -0.463 & 0.651 \\
\hline $\mathrm{X}_{1} \mathrm{X}_{4}$ & 2.6525 & 2.083 & 1.273 & 0.227 \\
\hline $\mathrm{X}_{2} \mathrm{X}_{3}$ & 8.895 & 2.083 & 4.270 & 0.001 \\
\hline $\mathrm{X}_{2} \mathrm{X}_{4}$ & 1.6525 & 2.083 & 0.793 & 0.443 \\
\hline $\mathrm{X}_{3} \mathrm{X}_{4}$ & 6.6775 & 2.083 & 3.206 & 0.008 \\
\hline
\end{tabular}

\section{Experimental versus predicted}

The evaluation between the observed and predicted values from the model is presented in Figure 4. The predicted and actual values of the model are similar and this proved the accuracy of the model.

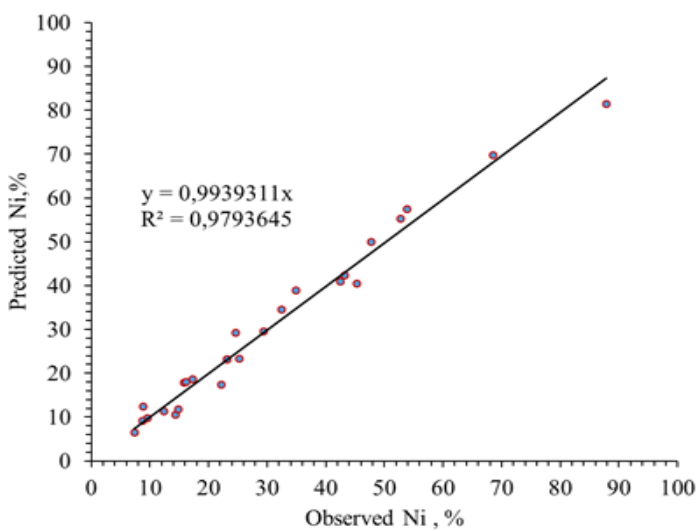

Figure 4. The actual and predicted plot for Ni dissolution recoveries.
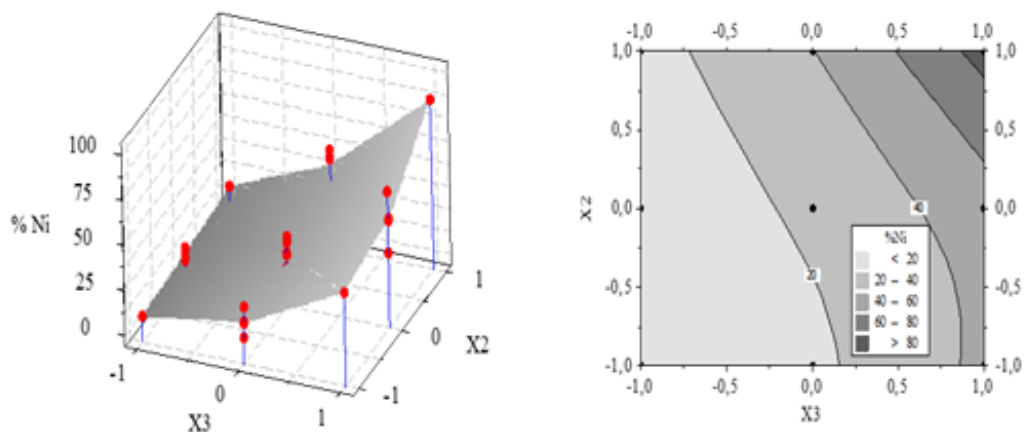

Figure 5. Effects of temperature $\left(X_{2}\right)$ and acid concentration $\left(X_{3}\right)$ on recovery of nickel.

\section{Three-dimensional graphics (3D) response surface}

The 3D response surface plots are a graphical representation can be prepared as a function of two factors, keeping all other parameters at constant levels, and these graphs are useful for understanding the relationship between the response and experimental levels of each variable and the interaction effects between the variables [16,23-25].

Figure 5 shows the 3D response surface relationship between temperature $\left(X_{2}\right)$ and acid concentration $\left(X_{3}\right)$ with recovery of nickel. It is obvious that the highest recovery could be achieved with the maximum level of temperature $\left(X_{2}\right)$ and acid concentration $\left(X_{3}\right)$. Figure 6 shows the 3D response surface relationship between dissolution time $\left(X_{4}\right)$ and temperature $\left(X_{2}\right)$ with recovery of nickel. It is clear that the highest recovery could be achieved with the maximum level of temperature $\left(X_{2}\right)$ and center level of time dissolution $\left(X_{4}\right)$. Figure 7 shows the $3 \mathrm{D}$ response surface relationship between temperature $\left(X_{2}\right)$ and stirring speed $\left(X_{1}\right)$ with recovery of nickel. It is appear that the highest recovery could be achieved with the maximum level of temperature $\left(X_{2}\right)$ and center level of stirring speed $\left(X_{1}\right)$. Figure 8 shows the 3D response surface relationship between time dissolution $\left(X_{4}\right)$ and acid concentration $\left(X_{3}\right)$ with recovery of nickel. The highest recovery was obtained at maximum level of acid concentration $\left(X_{3}\right)$ and center level of time dissolution $\left(X_{4}\right)$. Figure 9 shows the 3D response surface relationship between stirring speed $\left(X_{1}\right)$ and acid concentration $\left(X_{3}\right)$ with recovery of nickel. It is seen that the highest recovery could be achieved with the maximum level of acid concentration $\left(X_{3}\right)$ and center level of stirring speed $\left(X_{1}\right)$. Figure 10 shows the $3 \mathrm{D}$ response surface relationship between stirring speed $\left(X_{1}\right)$ and time dissolution $\left(X_{4}\right)$ with recovery of nickel. It is seen that that the highest recovery could be achieved with the center level of stirring speed $\left(\mathrm{X}_{1}\right)$ and dissolution time $\left(\mathrm{X}_{4}\right)$. Three-dimensional response surface and contour graphs showed similar results and they supported each other. 

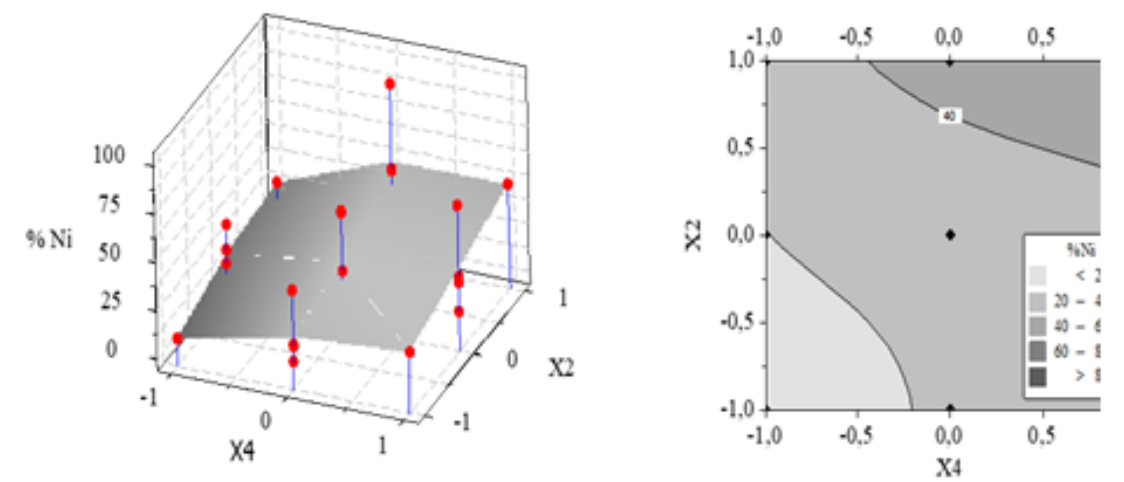

Figure 6. Effects of dissolution time $\left(\mathrm{X}_{4}\right)$ and temperature $\left(\mathrm{X}_{2}\right)$ on recovery of nickel.
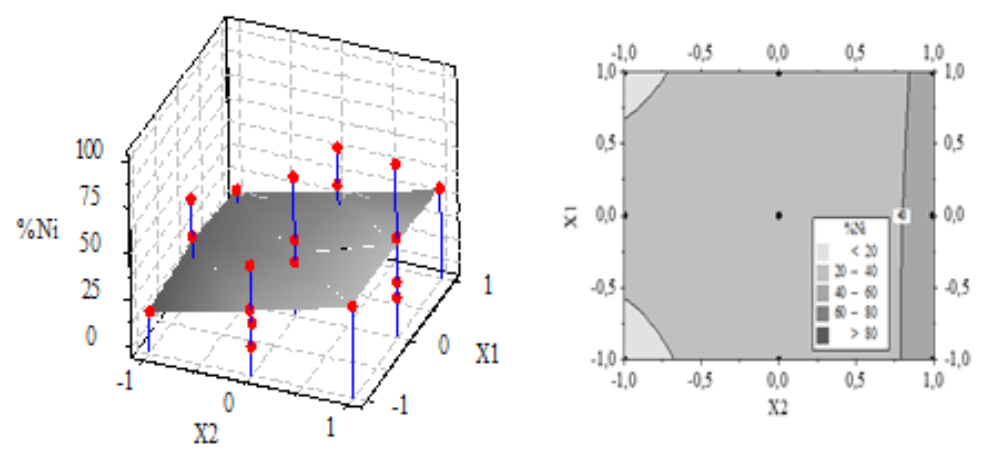

Figure 7. Effects of temperature $\left(X_{2}\right)$ and stirring speed $\left(X_{1}\right)$ on recovery of nickel.
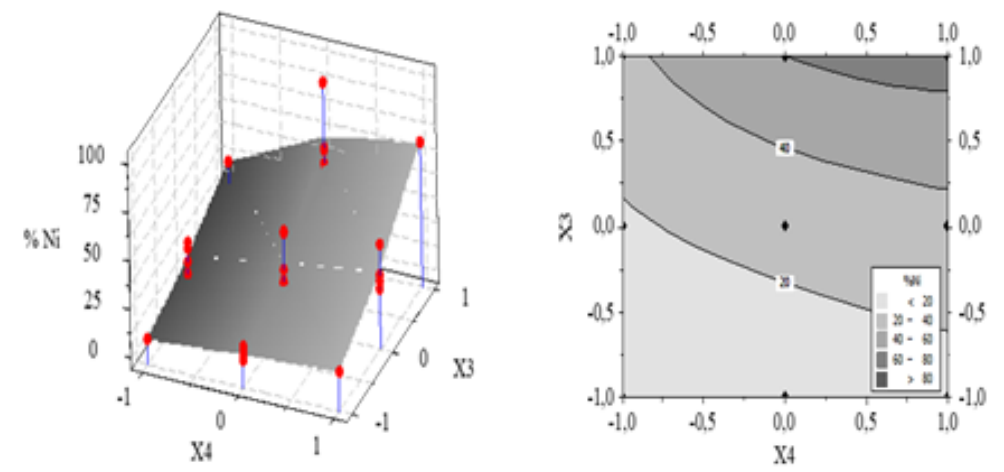

Figure 8. Effects of dissolution time $\left(\mathrm{X}_{4}\right)$ and acid concentration $\left(\mathrm{X}_{3}\right)$ on recovery of nickel.
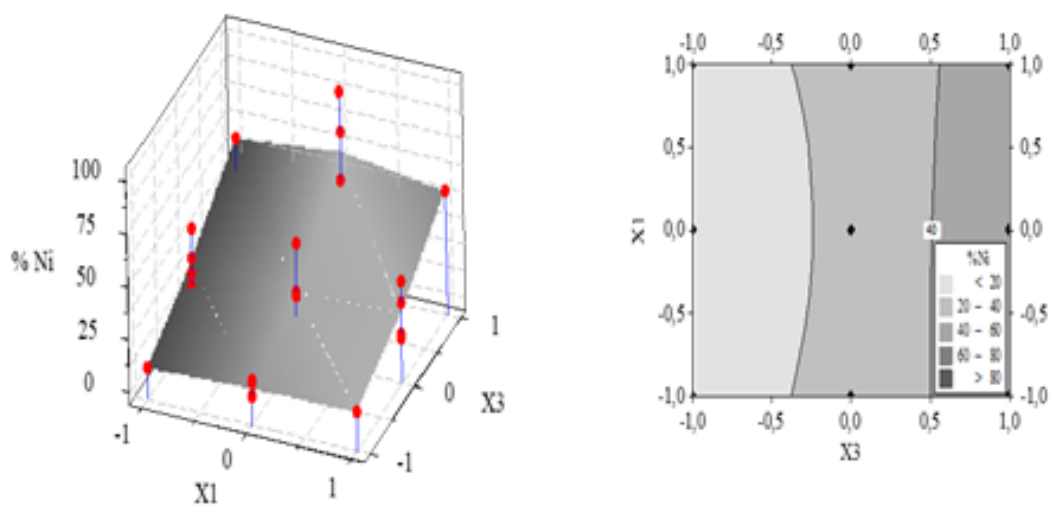

Figure 9. Effects of stirring speed $\left(X_{1}\right)$ and acid concentration $\left(X_{3}\right)$ on recovery of nickel. 


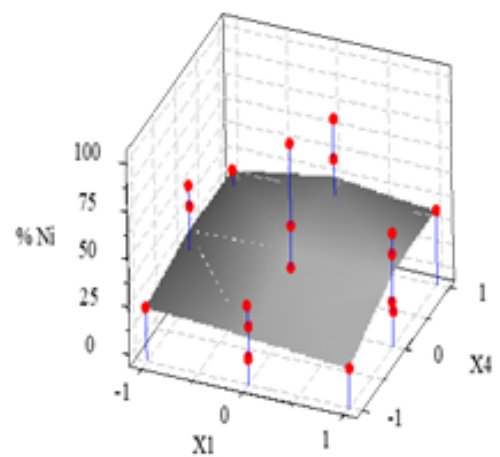

Figure 10. Effects of stirring speed $\left(X_{1}\right)$ and dissolution time $\left(X_{4}\right)$ on recovery of nickel.

\section{Conclusion}

In this study, a Box-Behnken design was applied for modeling and optimization of some operating variables on the leaching of nickel from lateritic ore from Eskişehir (Mihalıççık-Yunusemre). The variables studied were stirring speed, temperature, acid concentration and dissolution time. After leaching experiments, the highest $\mathrm{Ni}$ dissolution percentages were obtained as $87.85 \%$. The results obtained from the experiments were subjected to ANOVA and multiple regression analysis by using Minitab 16.0 software. The $R^{2}$ value of the model for nickel dissolution was calculated as 0.980 . This showed that the predicted values are in good agreement with the observed values. In order to gain a better understanding of the effect of the variables on nickel dissolution, three dimensional response surface and contour graphs were created and the results were examined.

\section{Acknowledgements}

The author Mohamed Taha Osman wishes to express sincere thanks to his supervisor in Konya Technical University, Department of Mining Engineering (Faculty of Engineering) Associate Professor Dr. Tevfik Agacayak for his honest help and kind support.

\section{References}

1. Li, Jinhui, Daoling Xiong, Hao Chen, Ruixiang Wang, and Yong Liang. "Physicochemical factors affecting leaching of laterite ore in hydrochloric acid." Hydrometal/129 (2012): 14-18.

2. Mudd, Gavin M. "Global trends and environmental issues in nickel mining: Sulfides versus laterites." Ore Geol Rev 38 (2010): 9-26.

3. Hallberg, Kevin, Barry Grail, Chris ADu Plessis, and Barrie Johnson "Reductive dissolution of ferric iron minerals: a new approach for bioprocessing nickel laterites." Minerals Eng 24 (2011): 620-624.

4. Golightly Paul. "Nickeliferous laterite deposits." (1981).

5. Baghalha, Morteza, and Vladimiros G. Papangelakis. "Pressure acid leaching of laterites at $250 \mathrm{C}$ : a solution chemical model and its applications." Metall Mater Trans B 29 (1998): 945-952.

6. Sukla, Lala Behari, and Vinita Panchanadikar. "Bioleaching of lateritic nickel ore using a heterotrophic micro-organism." Hydrometal/32 (1993): 373-379.

7. Georgiou, Dimitrios, and Vladimiros Papangelakis. "Sulphuric acid pressure leaching of a limonitic laterite: Chemistry and kinetics." Hydrometall 49 (1998): 23-46.

8. Park, Khi, and Cw Nam. "Status and prospect of nickel resources and processing." Trending Metals Mater. Eng 21 (2008): 1-9.

9. Zuniga, Mariela, and Edouard Asselin. "Leaching of a limonitic laterite in ammoniacal solutions with metallic iron." Hydrometal/104 (2010): 260-267.

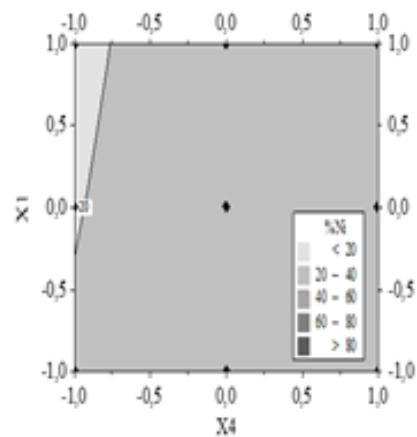

10. Agacayak, Tevfik, Veysel Zedef, and Salih Aydogan. "Leaching of lateritic nickel ores of Karacam (Eskisehir-Turkey) with hydrochloric acid." Int Multidiscip Sci Geoconf SGEM1 (2011): 1155.

11. Ayanda, Olushola Sunday, Folahan A Adekola, Alafara A Baba, and Olalekan S Fatoki, et al. "Comparative study of the kinetics of dissolution of laterite in some acidic media." (2011).

12. Sahu, Sha, Kavuri Nc, and Mu Kundu. "Dissolution kinetics of nickel laterite ore using different secondary metabolic acids." Brazilian J Chem Eng 28 (2011): 251-258.

13. Agacayak, Tevfik, Veysel Zedef, and Salih Aydogan. "Leaching of lateritic nickel ores of Karacam (Eskisehir-Turkey) with hydrochloric acid." Int Multidiscip Sci Geoconf SGEM1 (2011): 1155.

14. Ma, Baozhong, Chengyan Wang, Weijiao Yang, and Bo Yang, et al. "Selective pressure leaching of Fe (II)-rich limonitic laterite ores from Indonesia using nitric acid." Minerals Eng 45 (2013): 151-158.

15. Mohammadreza, Fatahi, Noaparast Mohammad, and Shafaei Seyyed Ziaeddin. "Nickel extraction from low grade laterite by agitation leaching at atmospheric pressure." Int J Min Sci Techno/24 (2014): 543-548.

16. Polat, Sevgi, and Perviz Sayan. "Application of response surface methodology with a Box-Behnken design for struvite precipitation." Adv Powder Techno/30 (2019): 2396-2407.

17. Koca, Sabiha, Derya Oz Aksoy, Ahmet Cabuk, and Pinar Aytar Celik, et al. "Evaluation of combined lignite cleaning processes, flotation and microbial treatment, and its modelling by Box Behnken methodology." Fue/192 (2017): 178-186.

18. Özgen, Selçuk, and Ahmet Yildiz. "Application of Box-Behnken Design to Modeling the Effect of Smectite Content on Swelling to Hydrocyclone Processing of Bentonites with Various Geologic Properties." Clays and Clay Minerals 58 (2010): 431-448.

19. Bagheri, Ahmad Reza, Mehrorang Ghaedi, Arash Asfaram, and Ramin Jannesar, et al. "Design and construction of nanoscale material for ultrasonic assisted adsorption of dyes: application of derivative spectrophotometry and experimental design methodology." Ultrason Sonochem 35 (2017): 112-123.

20. Ferreira, Sergio Luis Costa, Roy Bruns, Hadla Sousa Ferreira, and Geraldo Domingues Matos, et al. "Box-Behnken design: an alternative for the optimization of analytical methods." Anal Chim Acta 597 (2007): 179-186.

21. Körbahti, Bahadır, and Selin Tasyurek. "Electrochemical oxidation of ampicillin antibiotic at boron-doped diamond electrodes and process optimization using response surface methodology." Environ Sci Pollut Res 22 (2015): 3265-3278.

22. Akbay, Ismail Kutlugun, Ahmet Gungor, and Tonguç Ozdemir. "Optimization of the vulcanization parameters for ethylene-propylene-diene termonomer (EPDM)/ground waste tyre composite using response surface methodology." Polym Bull74 (2017): 5095-5109.

23. Tanyildizi, Muhammet Saban, Dursun Ozer, and Murat Elibol. "Optimization of a -amylase production by Bacillus $\mathrm{sp}$. using response surface methodology." Process Biochem 40 (2005): 2291-2296. 
24. Haider, Ali, and Pakshi Rajan. "Screening and optimization of media constituents for enhancing lipolytic activity by a soil microorganism using statistically designed experiments." Appl Biochem Biotechnol 141 (2007): 377-390.

25. Vazi Feh, Esmaeil Jorjani, and Bagh Erian. "Optimization of reagent dosages for copper flotation using statistical technique." Transactions of Nonferrous Metals Society of China 20 (2010): 2371-2378.
How to cite this article: Tevfik Agacayak and Ahmed Mohamed Taha Osman Abdelraheem. "Optimization and Modeling of Leaching Parameters Affecting Nickel Dissolution from Lateritic Ore in Eskisehir (Mihaliccik-Yunusemre) Using Box-Behnken Experimental Design". J Environ Anal Chem 7 (2020). 